\title{
Los años que vivimos en viñetas. Breve sociología sentimental del tebeo en tiempos de Franco.
}

\author{
Antonio Altarriba
}

Antonio Altarriba es catedrático de literatura francesa en la Universidad del País Vasco. Le interesan los aspectos visuales de la escritura y las posibilidades narrativas de la imagen. También la literatura erótica. Sobre ello ha escrito libros como La España del tebeo (2001), Tintín y el loto rosa (2007), Los tebeos de la transición (2008) o La paradoja del libertino (2008). Guionista, es autor de álbumes de historieta como Detective (1991), Amores locos (2005), El brillo del gato negro (2008), El arte de volar (2009) o El paso del tiempo (2011) y de series fotográficas recogidas en El elefante rubio (2007) o Vida salvaje (2008). Como escritor de ficción ha publicado El filo de la luna (1993), Cuerpos entretejidos (1996), Contratiempos (1996), La memoria de la nieve (2002) o Maravilla en el país de las Alicias (2010). Una selección de sus artículos en prensa aparece en Contra corriente (2000). 
En tiempos de Franco las viñetas son el mejor sitio para irse a vivir. No está al alcance de todos el hacerlo, pero los niños, todavía alejados del miedo a la represión y reacios a identificarse con la mitología del régimen, pueden permitírselo. Y acuden por legiones a instalarse en los geométricos cubículos, inquilinos de la imagen, ocupas de la aventura. Las páginas reticuladas no ofrecen mucho espacio y con ese papel de pulpa empastado de tinta las condiciones sanitarias dejan mucho que desear. Pero a los chavales no les preocupa ni la higiene ni la habitabilidad de su domicilio gráfico. Aunque la vivienda no sea nada del otro mundo, las vistas contienen precisamente la posibilidad de todos los mundos. $\mathrm{Y}$ eso es lo que importa. Las viñetas proporcionan un habitáculo mínimo, sin cocina ni cuarto de baño ni tan siquiera dormitorio porque, como es sabido, la historieta está liberada de cualquier esclavitud fisiológica, pero su amplio vano da directamente a la fantasía y eso en aquella España gris, firme ante el yugo y las flechas y atemorizada por la omnipresencia del pecado, es, más que un lujo, un auténtico milagro. Así que muchos se instalan en las viñetas, las habitan en cuerpo y alma y, a pesar de los rigores de la época, entre sus paredes viven una infancia repleta de magia, con momentos de plenitud, aunque sea encasillada.

Como ocurre con casas y pisos, las viñetas se pueden tener en propiedad o vivir en ellas alquilado, realquilado, incluso provisional y graciosamente hospedado. En el mundo de los tebeos hay latifundistas, modestos propietarios, acogidos de protección oficial, chabolistas y también indigentes. La economía de la viñeta determina las relaciones y establece jerarquías entre la chiquillería. Hay que reconocer que siempre fue una economía extraordinariamente aquilatada del céntimo o, como mucho, de la peseta, pero en la sutil escala de valores de la infancia eso basta para cimentar un prestigio o para hundirlo. Salvo escasas excepciones, la industria historietística se adapta a la capacidad adquisitiva de su público, haciendo un producto asequible aunque sea a costa de la calidad del papel o del salario de los dibujantes. Así que el precio del cuadernillo oscila entre los diez o veinticinco céntimos a principios de los cuarenta hasta las cinco pesetas en la segunda mitad de los sesenta. Ese es un momento decisivo en la historia de la recepción del tebeo pues la barrera del duro marca un antes y un después en la economía de la viñeta y en su sociología derivada. En ese decisivo punto de inflexión la historieta deja de ser la base de numerosos circuitos de préstamo e intercambio para convertirse en producto desechable, sin otro valor que el de su consumo puntual, ya sin capacidad de circulación ni de negociación entre los lectores. La España de la prosperidad acaba con los complejos rituales que rodean la adquisición y lectura de historietas y hacen de este medio, además de un soporte lúdico y cultural, un recurso esencial en la socialización infantil.

En los años cuarenta, en los cincuenta y hasta bien entrados los sesenta el tebeo es un producto a medio camino entre el lujo y la necesidad. Su aparición semanal en los quioscos suscita la contemplación fascinada de las nuevas portadas y desencadena un curioso proceso en el que se mezclan la excitación, la curiosidad y la maquinación más o menos maquiavélica para la compra. En un primer movimiento el colorista objeto de deseo es confrontado con las reservas pecuniarias que en general no superan la habitual calderilla de bolsillo. Ante la imposibilidad de adquirirlo sólo caben dos salidas que, lejos de ser excluyentes, funcionan de manera complementaria. Por una parte hay que idear la trama de financiación que, vía padres, tíos, hermanos mayores, incluso alianza con otros compañeros permita reunir la suma necesaria. Por otra parte y para paliar la desazón de la espera, cabe imaginar a partir de la portada el contenido del cuadernillo y, en función del conocimiento previo del folletín, inventar el continuará más verosímil. En cualquier caso y hasta que los planes se cumplen y por fin el tebeo llega a manos del lector transcurren 


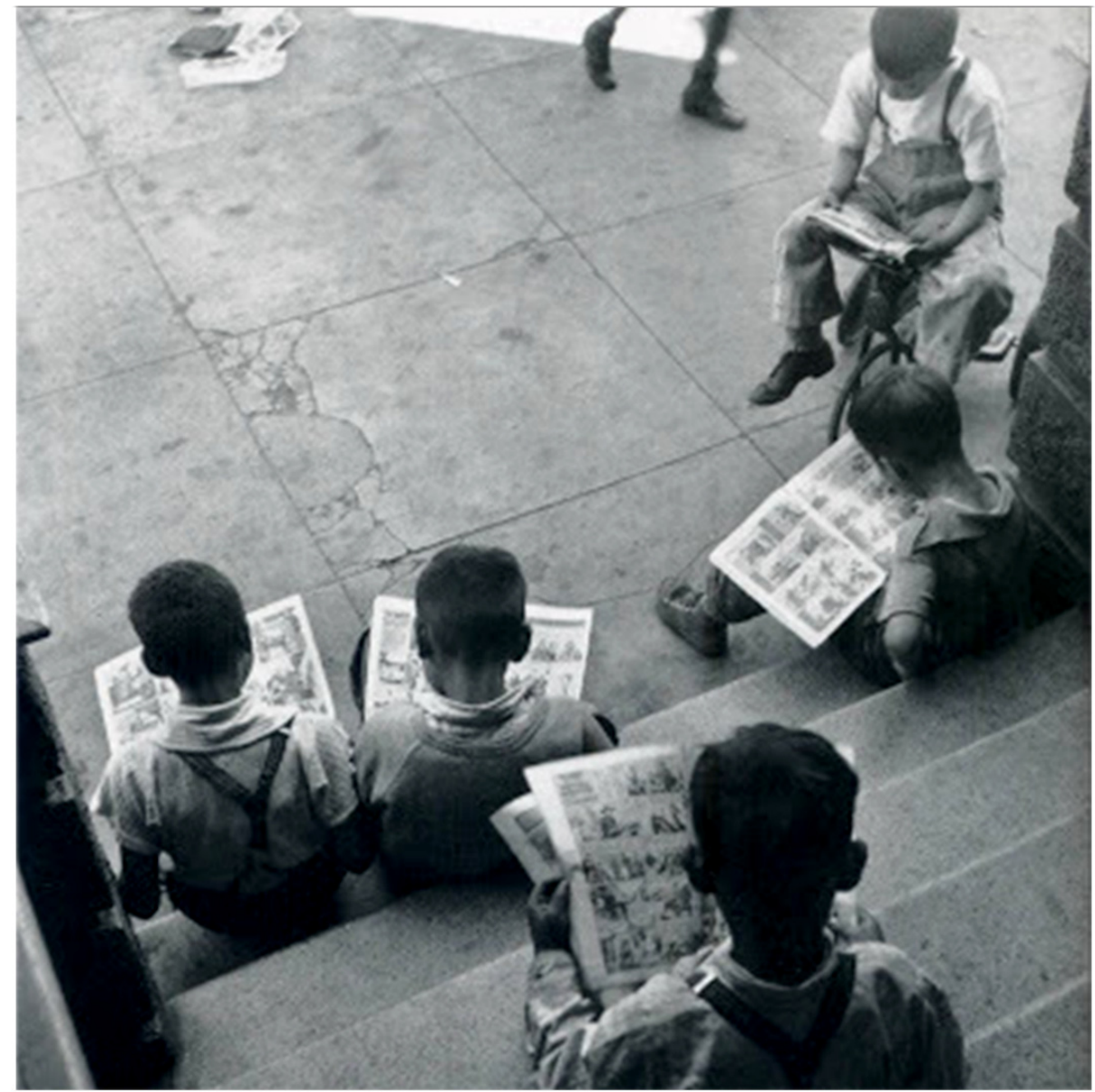

FIG. 1. Kids reading comics. (C) John Gutmann.

días de comportamiento ejemplar, de ofrecimiento para el recado recompensado o de tozudas demandas que, en caso de fracaso, desembocan en la frustración.

En general y salvo los casos más desfavorecidos el objetivo se puede conseguir, quizá no todas las semanas pero sí con la frecuencia suficiente como para no caer en la marginación tebeística. La propina familiar puede verse incrementada por los donativos de parientes que en visitas o en encuentros casuales acostumbran a entregar unas monedas a los más pequeños. Es la manera de redondear la peseta o las dos cincuenta que cuesta el tebeo. Pero la empresa no resulta fácil. Son momentos de extraordinaria tensión porque se hallan repartidos entre la insistente generosidad de los parientes y la prohibición paterna de aceptarla. Coger dinero de los otros puede interpretarse como señal de avaricia o, peor aún, de pobreza. El corazón del habitante de las viñetas oscila por lo tanto entre la obediencia debida y las posibilidades de adquisición que se abren con la dádiva. Normalmente y a pesar del probable castigo, vence la tentación consumista. Todo por los tebeos. Y es que la economía infantil, alimentada por la propina y limitada por la buena educación, se calibra por el nivel de una hucha en bancarrota permanente, por las golosinas, por las canicas y por otros cotizados juguetes, pero el verdadero baremo, el IBEX de este mercado de ilusión y colorín lo marcan los tebeos.

Un gesto esencial para consolidar la amistad consiste en enseñar la colección de tebeos. Es una manera de decir estos son mis poderes, indicio clave de la posición que se ocupa en el mundo, demarcación del territorio pero también atisbo de generosidad porque 
enseñarla es una manera de ofrecerla. Algunos poseen colecciones de las de permanecer boquiabierto y pasar horas enteras contemplando portadas, manoseando cuadernillos, comprobando su distribución por series y descubriendo ejemplares nunca vistos. El prestigio de estos potentados está, por supuesto, garantizado porque, aunque su compañía no resulte agradable, siempre permite descubrir desconocidas parcelas de ficción. En cualquier caso las condiciones de acceso a las propiedades historietísticas constituyen una muestra inequívoca de la personalidad del propietario. En la manera de entregarlas o de negarlas, se refleja su mezquindad, su sadismo o su generosidad. Pero, aunque los magnates no son raros, la mayoritaria clase media de la historieta se desenvuelve con un fondo de unas cuantas decenas de ejemplares. Es suficiente para mantenerse en el mercado de la ficción y, con una hábil gestión de préstamos e intercambios, lograr un nivel aceptable de renovación y hasta el acceso a los más recientes lanzamientos.

Una buena parte de la subsistencia tebeística pasa por una red secundaria de distribución extraordinariamente tupida y todavía hoy no muy bien estudiada ni en su estructura ni en sus repercusiones mediáticas. En míseros y casi siempre oscuros locales, mezcla de papelería, tienda de chucherías y quiosco, pueden cambiarse tebeos. El habitante de las viñetas sólo necesita acudir con los cuadernillos de los que quiere deshacerse y unas pocas monedas. Bastan diez o veinte céntimos por ejemplar, es decir diez o quince veces menos que el precio de portada, para salir con las provisiones de fantasía renovadas. Detrás del mostrador o en un rincón apartado se apilan cientos de tebeos de tacto seboso, portada desgarrada y a menudo ya sin grapas. Entre ellos hay que elegir. Han pasado por otras muchas manos y a menudo resultan prácticamente inaprovechables. El tendero los muestra con la displicencia con la que se trata al cliente de segunda, pero en medio de tanta viñeta en ruinas se ocultan no pocas sorpresas y, además, es la mejor manera de descubrir que el héroe preferido tuvo un pasado trepidante. $\mathrm{Y}$ aún existen otras fórmulas baratas para incrementar las reservas de historieta. Los sobres sorpresa contienen tras su opaco envoltorio y junto con un "indio" y algún chicle un par de tebeos por el módico precio de una peseta. Y también, aunque esto sea menos habitual, se saldan colecciones de escaso éxito.

Así pues, durante al menos los veinticinco primeros años de franquismo, los tebeos son mucho más que una industria. Las diversas vías para su adquisición no sólo colocan a cada cual en su sitio sino que generan comportamientos y forjan actitudes. Favorecen la ingeniería de la capitalización, la capacidad de negociación y, según los individuos y las circunstancias, pueden llevar al más desinteresado desprendimiento o a la conspiración casi delictiva. Pero, sin duda, el más saludable efecto de los tebeos lo propicia la semana de intervalo que separa un número de otro. Es el momento del comentario y de la valoración de la aventura, de la defensa pública del personaje preferido frente a otros de creciente aceptación. Se desarrolla así una retórica subsidiaria de la viñeta y fundamental para conquistar una posición en el grupo. Sin olvidar que el lapso entre entrega y entrega sólo se sobrelleva con impaciencia y capacidad fabuladora ¿Cómo saldrá nuestro héroe de la apurada situación en la que ha quedado en la última viñeta? Las hipótesis, razonables o descabelladas, se debaten, se aceptan o se rechazan hasta que acaban invalidadas por la aparición del siguiente episodio que a menudo queda por debajo del inventado por los lectores. De esa manera para varias generaciones de españoles los tebeos no sólo son refugio contra la monotonía y evasión de la miseria sino, ante todo, escuela de la imaginación. 